TPeriodica Polytechnica Civil Engineering

\author{
62(4), pp. 1007-1014, 2018 \\ https://doi.org/10.3311/PPci.11818 \\ Creative Commons Attribution (i)
}

\title{
Study of the Properties of Renovation Plasters as a Function of Air Content and Porosity Using an Orthogonal Design of Experiment
}

\author{
Waclaw Brachaczek ${ }^{1 *}$
}

Received 13 December 2017; Revised 08 March 2018; Accepted 04 July 2018

\begin{abstract}
The main message of the article is an analysis of the impact of: the aerating agent, cement, polymer additives, cellulose ethers, and perlite on renovation plaster porosity. To determine the impact, an orthogonal design of experiment proposed by Taguchi was used. The results show that the air content in the mixture does not necessarily indicate high porosity of the hardened mortar and vice versa. This is because not all of the factors analyzed in this experiment have significant impacts on the output. In terms of air content in fresh mortar, cement and aerating agent are significant factors. In terms of porosity in fresh mortar, cement, aerating agent, perlite and cellulose ethers are significant factors. Additionally, the studies are presented to explain the impacts of these ingredients.
\end{abstract}

\section{Keywords}

renovation plasters, microstructure of the renovation plaster, porosity, Taguchi design model, orthogonal model and results

\footnotetext{
1 Faculty of Materials, Civil and Environmental Engineering University of Bielsko-Biala Ul. Willowa 2, 43-300 Bielsko-Biala,

* Corresponding author, email:wbrachaczek@ath.bielsko.pl
}

\section{Introduction}

Renovating plasters are used for restoring damp and salted walls. One of the important characteristics distinguishing these materials from traditional cement-limestone plasters is their porosity. Although renovation plasters have been used for several decades, and in many cases benefits of using them are obvious, there are also many reservations [1-4]. The main problems encountered by contractors using these materials include the appearance of cracks when drying, peeling both immediately after application and in use, the emergence of salt efflorescence, low cohesion of plasters and difficulties in application and processing, which is an important factor determining the contractors' choice [5]. One of the reasons for these problems is the low porosity of such plasters. The open porosity of a renovation plaster should be over $45 \%$, which is related to their ability to store salt and not be destroyed by crystallization [6]. The available literature contains premises specifying the influence of selected components on the microstructure of mortars. This proves that the issue is still a current topic of research.

The most important material factors, which shape the microstructure of the hardened mortar, are the type and quantity of the aerating agent, the size and the share of mineral ingredients - primarily the powdery fractions, type and amount of plastificators and superplastificators, or other admixtures, e.g. hydrophobizing admixture, w/c ratio, the quantity and the cement type, water etc. [7-9].

\subsection{The factors influencing the porosity}

Most aerating agents stabilize the foam in the mortar by means of physicochemical interactions, among them, anionic ones are of greatest importance [10]. They include a group of compounds along with functioning group such as: n-alkyl carboxylates (n-RCOO-), n-alkyl sulfonates (n- $\mathrm{RSO}_{3}^{-}$) and n-alkyl sulfates (n- $\mathrm{RSO}_{4}^{-}$). The lengths of the hydrocarbon chains are between $\mathrm{C}_{7}$ and $\mathrm{C}_{16}$, Fig. 1 presents some types of aerating agents.

Another material impacts are aggregate and cement. Powers $[11,12]$ demonstrated that the size of the air bubbles is largely dependent on the size of the aggregate; the increase in the dusty fraction caused the amount of air bubbles to decrease. 

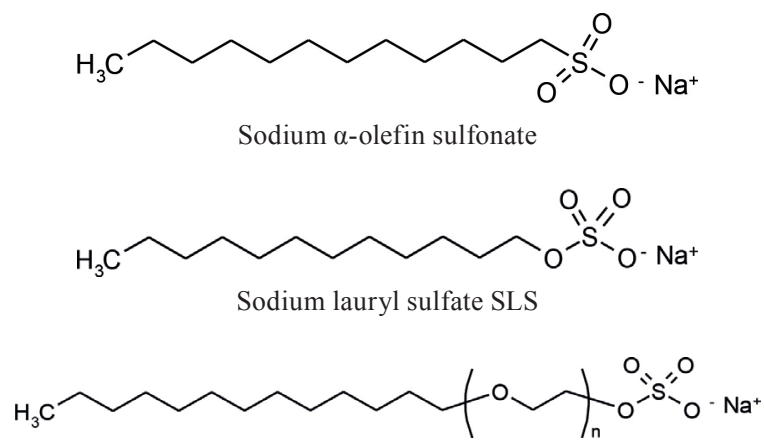

Sodium laureth sulfate (sodium lauryl ether sulfate) SLES

Fig. 1 Types of aerating agents

On the other hand, the aggregate is involved in the stabilization of the air bubbles. According to Powers [11] this is due to the adsorption of the aerating agents on the surface of the solids, which may be different for different aggregates and depends on their chemical composition and processing type. According to Backstrom [13] the adhesion of air bubbles may also occur on cement particles. To explain the mechanism of stabilization of air bubbles on the surface of cement, Du [7] suggested the Gibbs-Marangoni isotherm. The author stated that the surface phase differs from the interior of the liquid phase in composition. The surface of the cement particles has a high surface energy. Adsorbed admixture particles on the surface of cement grains, or on the surface of formed hydrates, lower this energy. Sugiura [14] demonstrated that the type of cement and the type of polymer additive impact the mortar porosity. High efficiency in improving porosity is achieved by using other components such as porous aggregates: zeolites and perlites $[15,16]$. Besides material factors, the microstructure depends on the method of mortar mixing [17].

\subsection{An orthogonal design by Taguchi}

An orthogonal design of experiment by Taguchi can be used to determine the impact of the factors on the properties of the mortars. This design has proved successful in experimental optimization of the quality of multi-parameter processes and technical objects. The method can be used to optimize a new product as well as to improve existing products [18]. The design of experiment is an orthogonal design when the n-dimensional columns of the measurement array are orthogonal to each other as vectors in the $\mathrm{Rn}$ space. These designs have many advantages from a statistical standpoint. In particular, omission of certain parts in the model does not necessitate the conversion of estimates of the remaining parameters, as long as measurements are made according to the orthogonal design for this model $[18,19]$.

\section{Materials and methods}

\subsection{The purpose of the study}

The purpose of this study was to analyze the impact of selected admixtures, cement and light aggregate on the aeration and porosity of renovation plasters. In order to reduce the number of experiments with a balanced statistical scatter and comparability, Taguchi orthogonal design of experiment was used. Among the large number of factors that could influence the aeration of the mortar and the porosity of the plasters, five variables $x_{s}(s=1,2,3, \ldots, \mathrm{S})$ were selected for this study. These were cement, polymer additive, cellulose ethers, aerating agents and lightweight aggregate - perlite. Factors whose impact on porosity and aeration have not been analyzed were fixed as constant. The time to mix the ingredients was also the same.

\subsection{The subject of the research}

The research was carried out on the original recipe of renovation plasters with the composition shown in Table 2. The factors influencing the air content in fresh mortar $\mathrm{L} \%$ and the open porosity Pc \% were as follows: hydroxypropyl methylcellulose (HPMC), for which the proportion of methoxy groups $\left(\mathrm{OCH}_{3}\right)$ was $28-30 \%$ and hydroxypropyl groups $\left(\mathrm{OC}_{3} \mathrm{H}_{6} \mathrm{OH}\right)$ $3.0-5.0 \%$, with a viscosity determined at a $2 \%$ solution of 20 $000 \mathrm{mPa} \cdot \mathrm{s}$, terpolymer poly (vinyl acetate-VeoVa-acryl), and sodium C14-16 $\alpha$-olefin sulfonate. The type and composition of cement is presented in Table 1.

Variation ranges of individual components were determined on the basis of information in the technical data sheets of the raw materials as well as exploratory research.

Test specimens were prepared in the amount of $2000 \mathrm{~g}$ as dry ingredients. In each sample, the differences resulting from the change of ingredients were supplemented with aggregates (sand and limestone flour mixed in the ratio of 100 to 20). Dry ingredients were mixed with water using an automatic mortar mixer compliant with the requirements of PN-EN 1015-2:2000/

Table 2 Renovation plaster recipe together with variation range of factors

\begin{tabular}{lcc}
\hline Component & quantity $(\% \mathrm{wt} .)^{*}$ & description \\
\hline CEM I 42.5 Portland cement & $10.0 \div 24.0$ & binder 1 \\
hydrated white lime & 10.0 & binder 2 \\
poly (VAC/VeoVa/AC) & $0.5 \div 2.0$ & admixture \\
perlite EP 150 & $0.5 \div 2.0$ & lightweight aggregate \\
sodium lauryl sulfate (SLS) & $0.01 \div 0.08$ & aerating agent \\
cellulose admixture HPMC 52000 & $0.08-0.32$ & cellulose admixture \\
quartz sand 0.0 $\div 1.0 \mathrm{~mm}$ & to $100 \%$ & aggregate \\
limestone powder & sand x 20\% & filler \\
\hline
\end{tabular}

*Quantities refer to the sum of the dry components

Table 1 Chemical composition of Portland cement CEM I 42.5 R

\begin{tabular}{|c|c|c|c|c|c|c|c|c|c|c|c|}
\hline & \multicolumn{11}{|c|}{ ingredients (\% wt.) } \\
\hline & loss on ignition [\%] & $\mathrm{SiO}_{2}$ & $\mathrm{Al}_{2} \mathrm{O}_{3}$ & $\mathrm{Fe}_{2} \mathrm{O}_{3}$ & $\mathrm{CaO}$ & $\mathrm{MgO}$ & $\mathrm{Na}_{2} \mathrm{O}$ & $\mathrm{K}_{2} \mathrm{O}$ & $\mathrm{Cl}$ & $\mathrm{Na}_{2} \mathrm{O}_{\text {eq }}$ & $\mathrm{SO}_{3}$ \\
\hline CEM I 42,5R Górazdze & 2,71 & 20,04 & 5,07 & 2,35 & 63,94 & 1,72 & 0,17 & 0,77 & 0,065 & 0,68 & 2,81 \\
\hline
\end{tabular}


Table 3 Levels of factors in the orthogonal design of experiment

\begin{tabular}{|c|c|c|c|c|c|}
\hline \multirow{3}{*}{$\begin{array}{c}\text { Factor/ } \\
\text { Level }\end{array}$} & A & B & $\mathrm{C}$ & $\mathrm{D}$ & $\mathrm{E}$ \\
\hline & \multicolumn{5}{|c|}{ quantity ( $\%$ wt.) ${ }^{*}$} \\
\hline & cement & $\begin{array}{l}\text { polymer } \\
\text { additive }\end{array}$ & $\begin{array}{l}\text { cellulose } \\
\text { admixture }\end{array}$ & $\begin{array}{c}\text { aerating } \\
\text { agent }\end{array}$ & perlite \\
\hline 1 & 10.0 & 0.5 & 0.08 & 0.01 & 0.5 \\
\hline 2 & 14.0 & 1.0 & 0.16 & 0.03 & 1.0 \\
\hline 3 & 18.0 & 1.5 & 0.24 & 0.05 & 1.5 \\
\hline 4 & 24.0 & 2.0 & 0.32 & 0.08 & 2.0 \\
\hline
\end{tabular}

*Quantities refer to the sum of the dry components

A1:2007E [20]. Sample curing was carried out in accordance with PN-EN 1015-11: 2001[21]. All tests were performed with constant consistence of the mortar determined by flow table according to PN-EN 1015-3:2000/A2:2007[22], which was 170 $\pm 5 \mathrm{~mm}$. The air content was tested according to PN-EN 10157:2000 and porosity was tested based on WTA Merkblatt 2-0904/D Sanierputzsysteme[6].

\subsection{Orthogonal design of experiment}

In order to investigate the influence of individual factors on the scatter of the examined properties, a multivariate analysis of variance was used. In the analysis, for each factor the null hypothesis $\mathrm{H} 0$ was formulated: the influence of the factor was not proved. By using the test you can either reject the null hypothesis or state that the results of the experiment do not contradict the hypothesis. Four levels of $x_{s}$ variables were used in the experiment. These levels were determined by the amounts of individual components of the renovation plaster recipes. These levels were the amounts of individual components in the renovation plaster recipe. In the case of cement, the amounts were 10,14, 18 and 24\%. The other factors also reached one of four possible levels: the aeration admixture (0.08, 0.16, 0.24 and $0.32 \%$ ) and polymer addition $(0.5,1.0,1.5$ and $2.0 \%)$, respectively. The levels of factors in the orthogonal design of experiment are summarized in Table 3. The quantities of ingredients are expressed in percentage by mass in relation to the dry ingredients.

In order to apply the Taguchi approach, the L16 design of experiment (type B) was used to solve the problem [23].

$\begin{array}{cccccc}\mathrm{Nr} & \mathrm{X}_{1} & \mathrm{X}_{2} & \mathrm{X}_{3} & \mathrm{X}_{4} & \mathrm{X}_{5} \\ 1 & 1 & 1 & 1 & 1 & 1 \\ 2 & 1 & 2 & 2 & 2 & 2 \\ 3 & 1 & 3 & 3 & 3 & 3 \\ 4 & 1 & 4 & 4 & 4 & 4 \\ 5 & 2 & 1 & 2 & 3 & 4 \\ 6 & 2 & 2 & 1 & 4 & 3 \\ 7 & 2 & 3 & 4 & 1 & 2 \\ 8 & 2 & 4 & 3 & 2 & 1 \\ 9 & 3 & 1 & 3 & 4 & 2 \\ 10 & 3 & 2 & 4 & 3 & 1 \\ 11 & 3 & 3 & 1 & 2 & 4 \\ 12 & 3 & 4 & 2 & 1 & 3 \\ 13 & 4 & 1 & 4 & 2 & 3 \\ 14 & 4 & 2 & 3 & 1 & 4 \\ 15 & 4 & 3 & 2 & 4 & 1 \\ 16 & 4 & 4 & 1 & 3 & 2\end{array}$

According to this plan, 16 experiments were designed, as presented in Table 4. Numbers in parentheses indicate the levels adopted in the design of experiment.

Table 4 Orthogonal design of experiment and the experiment results

\begin{tabular}{|c|c|c|c|c|c|c|c|c|}
\hline \multirow{2}{*}{ No. } & $\begin{array}{l}\text { cement } \\
(\% \text { wt. })^{*}\end{array}$ & $\begin{array}{l}\text { polymer } \\
(\% \text { wt. })^{*}\end{array}$ & $\begin{array}{l}\text { cellulose } \\
\text { (\% wt.)* }\end{array}$ & $\begin{array}{c}\text { aerating agent } \\
(\% \mathrm{wt} .)^{*}\end{array}$ & $\begin{array}{l}\text { perlite } \\
(\% \text { wt. })^{*}\end{array}$ & $\begin{array}{c}\text { air contents } \mathrm{L} \\
(\%)\end{array}$ & $\begin{array}{c}\text { porosity } \mathrm{Pc} \\
(\%)\end{array}$ & $\begin{array}{c}\text { water } \\
(\% \text { wt. })^{*}\end{array}$ \\
\hline & A & B & $\mathrm{C}$ & $\mathrm{D}$ & $\mathrm{E}$ & & & \\
\hline 1 & $10.0(1)$ & $0.5(1)$ & 0.08 (1) & 0.01 (1) & $0.5(1)$ & 18.0 & 37.0 & 19.0 \\
\hline 2 & 10.0 & $1.0(2)$ & $0.16(2)$ & $0.03(2)$ & $1.0(2)$ & 22.0 & 40.0 & 22.0 \\
\hline 3 & $10.0(1)$ & $1.5(3)$ & $0.24(3)$ & 0.05 (3) & $1.5(3)$ & 27.0 & 44.0 & 27.0 \\
\hline 4 & $10.0(1)$ & $2.0(4)$ & $0.32(4)$ & $0.08(4)$ & $2.0(4)$ & 30.0 & 49.0 & 29.0 \\
\hline 5 & $14.0(2)$ & $0.5(1)$ & $0.16(2)$ & 0.05 (3) & $2.0(4)$ & 29.0 & 49.0 & 28.0 \\
\hline 6 & $14.0(2)$ & $1.0(2)$ & 0.08 (1) & $0.08(4)$ & $1.5(3)$ & 33.0 & 50.0 & 23.0 \\
\hline 7 & $14.0(2)$ & $1.5(3)$ & $0.32(4)$ & 0.01 (1) & $1.0(2)$ & 19.0 & 38.5 & 27.0 \\
\hline 8 & $14.0(2)$ & $2.0(4)$ & $0.24(3)$ & $0.03(2)$ & $0.5(1)$ & 24.0 & 37.0 & 22.0 \\
\hline 9 & $18.0(3)$ & $0.5(1)$ & $0.24(3)$ & $0.08(4)$ & $1.0(2)$ & 32.0 & 49.0 & 25.0 \\
\hline 10 & $18.0(3)$ & $1.0(2)$ & $0.32(4)$ & $0.05(3)$ & $0.5(1)$ & 29.0 & 42.0 & 25.0 \\
\hline 11 & 18.0 & $1.5(3)$ & 0.08 (1) & $0.03(2)$ & $2.0(4)$ & 27.0 & 46.0 & 28.0 \\
\hline 12 & $18.0(3)$ & $2.0(4)$ & $0.16(2)$ & 0.01 (1) & $1.5(3)$ & 22.0 & 43.0 & 25.0 \\
\hline 13 & $24.0(4)$ & $0.5(1)$ & $0.32(4)$ & $0.03(2)$ & $1.5(3)$ & 29.0 & 42.0 & 27.0 \\
\hline 14 & $24.0(4)$ & $1.0(2)$ & $0.24(3)$ & 0.01 (1) & $2.0(4)$ & 21.0 & 45.0 & 28.0 \\
\hline 15 & $24.0(4)$ & $1.5(3)$ & $0.16(2)$ & $0.08(4)$ & $0.5(1)$ & 36.0 & 48.0 & 23.0 \\
\hline 16 & $24.0(4)$ & $2.0(4)$ & $0.32(1)$ & $0.05(3)$ & $1.0(2)$ & 31.0 & 48.0 & 28.0 \\
\hline
\end{tabular}

The numbers in brackets indicate the factor value corresponding to the Taguchi design of experiment according to the adopted L16 model (type B). Quantities refer to the sum of the dry components 


\subsection{Methodology of results analysis}

Analysis of results of the scatter and variance were used for analyzing the factors based on the orthogonal design of experiment.

Based on the analysis of the resulting scatter, the most favorable composition of the mixture was determined as well as the order of impact in terms of air content $L(\%)$ and porosity $P c(\%)$. The ranges of factorial variation are presented in the tables in which $\mathrm{Ki}$ is the mean of the impacts of factors $\mathrm{A}$, B, C, D on the adopted levels, which equal 1, 2, 3, 4. Based on the analysis of variance, the order of impact of the factors and their share amounts were determined. Regression analysis was performed or 5 factors A, B, C, D, E - independent variables and for 2 dependent variables: $L(\%), P c(\%)$. This analysis was performed with the Statistica package using the multiple regression option. Complete linear and linear-quadratic regression models were determined only with significant factors at significance level of 0.05 . For each regression equation, the basic characteristics for evaluating the quality of a regression equation, such as the correlation coefficient $R$, the value of F-Snedecor statistics, the significance level for the whole regression equation and for individual factors were given. In order to assess the impact of the factor on the multiplicity of the dependent factor, the significance $p$-value was considered. The lower the value, the greater the impact of the factor.

The obtained regression equations can be used to predict the value of dependent $P c(\%)$ and $L(\%)$ variables. Additionally, a "prediction error" was calculated as a percentage of the estimation error divided by the mean value of the dependent variable. The value of this indicator shows what average error (expressed in percentage) is made while predicting the value of the dependent variable on the basis of the regression equation. Linear regression models can be used to predict the value of dependent variables, but they are insufficient to determine the value of local extremes, since linear functions do not have local extremes. The lowest and the highest values are taken on the boundary of the area of the independent variables (factors) range. Therefore, a quadratic regression analysis was also performed, taking into account only two independent variables with the lowest significance level. Once the quadratic regression equations were established, the plots of the corresponding surfaces were made, which show the extent of extreme values.

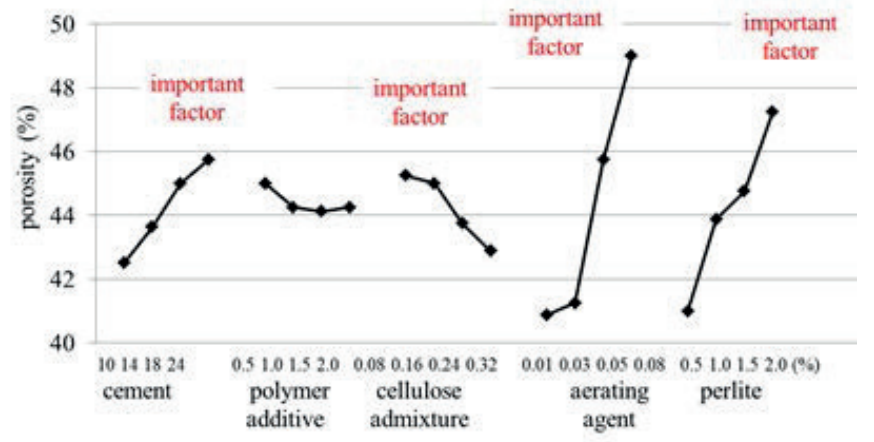

Fig. 2 Impact of the factors level on the air content in fresh mortar $L(\%)$

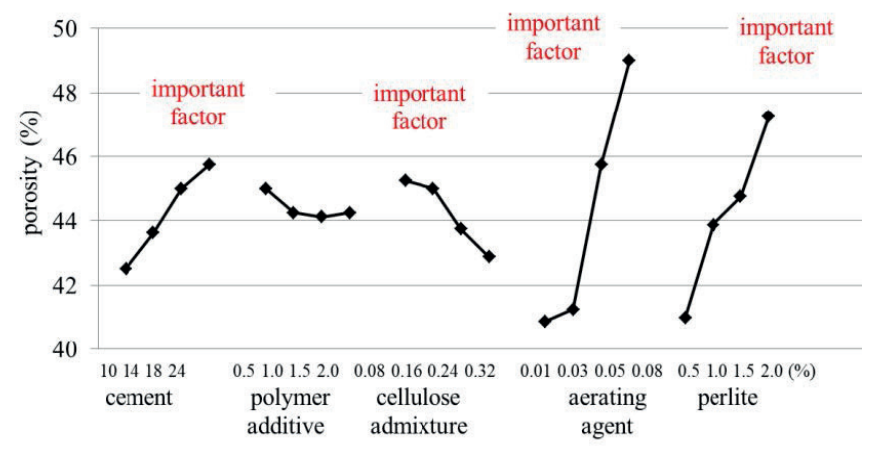

Fig. 3 Impact of the factors level on porosity of hardened mortar $P c(\%)$

\section{Results and their discussion 3.1 Analysis of factors variability}

The results of the orthogonal design of experiment are presented in Table 4. The expected scatter of impact of the factors on the air content $L(\%)$ in the fresh mortar is shown in Fig. 2 and on the porosity of the hardened mortar $P c(\%)$ in Fig. 3. The scope of the analysis resulting from the orthogonal design of experiment is presented in Table 5.

Based on the experimental data, a table was developed comprising a set of values for factors A, B, C, D, E for which the particular dependent variables have minimum and maximum values.

Analyzing the results presented in the table and graphically in the plots, the following conclusions can be drawn:

The order of influence of the factors on the air content $L$ (\%) in the fresh mortar is as follows: DABEC. This means that the predominant influence is that of aerating agent, and the D4 value is the most favourable. The second factor is cement, A4 is the optimum value. According to the same method of analysis, the values for the remaining components should correspond to $\mathrm{B} 3, \mathrm{E} 3$, and $\mathrm{C} 2$.

Table 5 The scope of analysis resulting from the orthogonal design of experiment

\begin{tabular}{|c|c|c|c|c|c|c|c|c|c|c|}
\hline & \multicolumn{5}{|c|}{ air content L ( $\%)$} & \multicolumn{5}{|c|}{ porosity Pc (\%) } \\
\hline & $\mathrm{A}$ & $\mathrm{B}$ & $\mathrm{C}$ & $\mathrm{D}$ & $\mathrm{E}$ & A & $\mathrm{B}$ & $\mathrm{C}$ & $\mathrm{D}$ & $\mathrm{E}$ \\
\hline $\mathrm{K} 1$ & 24.25 & 25.0 & 27.25 & 20.0 & 26.75 & 42.5 & 45.0 & 45.25 & 40.88 & 41.00 \\
\hline $\mathrm{K} 2$ & 26.25 & 26.25 & 27.25 & 25.5 & 26.0 & 43.63 & 44.25 & 45.00 & 41.25 & 43.88 \\
\hline $\mathrm{K} 3$ & 27.5 & 27.25 & 26.00 & 29.0 & 27.75 & 45.0 & 44.13 & 43.75 & 45.75 & 44.75 \\
\hline K4 & 29.25 & 26.75 & 26.75 & 32.75 & 26.75 & 45.75 & 44.25 & 42.88 & 49.00 & 47.25 \\
\hline Scope of analysis & 5.0 & 2.25 & 1.25 & 12.75 & 1.75 & 3.25 & 0.88 & 2.38 & 8.13 & 6.25 \\
\hline Optimum values & A4 & B3 & $\mathrm{C} 2$ & D4 & E3 & A4 & B1 & $\mathrm{C} 1$ & D4 & E4 \\
\hline
\end{tabular}


Table 6 Results of regression analysis - complete model for air content

\begin{tabular}{|c|c|c|c|c|}
\hline \multicolumn{2}{|c|}{ independent variables } & factors & significance level & significance \\
\hline \multicolumn{2}{|c|}{ free term } & 13.8607417 & 0.000000 & significant variable \\
\hline cement & $\mathrm{X} 1$ & 0.3424 & 0.000000 & significant variable \\
\hline polymer additive & $\mathrm{X} 2$ & 0.2788 & 0.505338 & non-significant variable \\
\hline cellulose admixture & $\mathrm{X} 3$ & -3.6394 & 0.189167 & non-significant variable \\
\hline aerating agent & $\mathrm{X} 4$ & 182.5321 & 0.000000 & significant variable \\
\hline perlite & $\mathrm{X} 5$ & 0.0242 & 0.952632 & non-significant variable \\
\hline
\end{tabular}

Regression equation:

$\mathrm{Y}=13.8607417+0.3424 \cdot \mathrm{X} 1-0.2788 \cdot \mathrm{X} 2-3.6394 \cdot \mathrm{X} 3+182.5321 \cdot \mathrm{X} 4+0.0242 \cdot \mathrm{X} 5$

Multiple correlation coefficient $\mathrm{R}=0,96001687$

F-Snedecor statistics: F(5.42) $=98.787$

Significance across the equation: 0.00000 equation is significant

Error of estimate: 1.5616

Error of estimate as a percentage of the mean $\mathrm{d}=5.82 \%$

Table 7 Results of regression analysis - complete model for porosity

\begin{tabular}{|c|c|c|c|c|}
\hline \multicolumn{2}{|c|}{ independent variables } & factors & significance level & significance \\
\hline \multicolumn{2}{|c|}{ free term } & 31.1447741 & 0.000000 & significant variable \\
\hline cement & $\mathrm{X} 1$ & 0.2765 & 0.000000 & significant variable \\
\hline polymer additive & $\mathrm{X} 2$ & 0.0535 & 0.888413 & non-significant variable \\
\hline cellulose admixture & X3 & -7.7920 & 0.003163 & significant variable \\
\hline aerating agent & $\mathrm{X} 4$ & 131.6212 & 0.000000 & significant variable \\
\hline perlite & $\mathrm{X} 5$ & 3.7164 & 0.000000 & significant variable \\
\hline
\end{tabular}

Regression equation:

$\mathrm{Y}=31.1447741+0.2765 \cdot \mathrm{X} 1+0.0535 \cdot \mathrm{X} 2-7.7920 \cdot \mathrm{X} 3+131.6212 \cdot \mathrm{X} 4+3.7164 \cdot \mathrm{X} 5$

Multiple correlation coefficient $\mathrm{R}=0.95380993$

F-Snedecor statistics: F(5.42) $=84.678$

Significance across the equation: 0.00000 equation is significant

Error of estimate: 1.4250

Error of estimate as a percentage of the mean $\mathrm{d}=3.21 \%$

In the case of porosity $P_{c}(\%)$, the order of influence is DEACB. The predominant influence is that of aerating agent, and the D4 value is the most favourable. Another factor is perlite, E4 is the most favourable value, followed by cement and cellulose ether. Values of other components should be A4, C1, and B1.

\subsection{The analysis of variance}

Complete linear regression models with analysis of variance of air content $L(\%)$ are presented in Table 6 . The significance of the impact of the examined factors and the order of impact of the examined factors as well as the their quantities were assessed on the basis of the p-value significance level.

\subsubsection{Air content $L(\%)$}

Based on the analysis of variance of the orthogonal design of experiment (Table 6) it can be concluded that the significance level $\mathrm{p}$ for the whole equation is close to zero, the value of F-Snedecor statistics $F$ (5.42) is 98.787, and the coefficient of multiple correlations is significantly different from 0 , i.e. the regression equation is significant which means that the impact of factors can be described using a linear model. A low error of estimation of $1.5616 \%$ allows to use the equation to predict the dependent variable. The most influential factors are the aerating agent and the cement, which shows that the results of the variance analysis coincide with the variance analysis.

\subsubsection{Porosity Pc}

Based on the analysis of variance of the orthogonal design of experiment for porosity (table 7), it can be stated that $F(5.42)$ is equal to 84.678 , the probability level $p$ is close to zero, and the coefficient of multiple correlation is significantly different from 0 , i.e. the regression equation is significant. Based on the magnitude of the significance level $p$, it can be stated that the greatest impact on the porosity is that of: cement, aerating agent, and perlite. It has also been found that the cellulose ether impacts the porosity negatively. The impact of the polymer additive is the lowest. Also in this case, the results of the analysis of variance coincide with those of the variation analysis.

\subsection{Material linear-quadratic models of two variables}

The obtained results allowed to create a material model describing the impact of the most important factors on the air content $L(\%)$ and porosity $P_{c}(\%)$. As a material model, a second degree polynomial was adopted. 


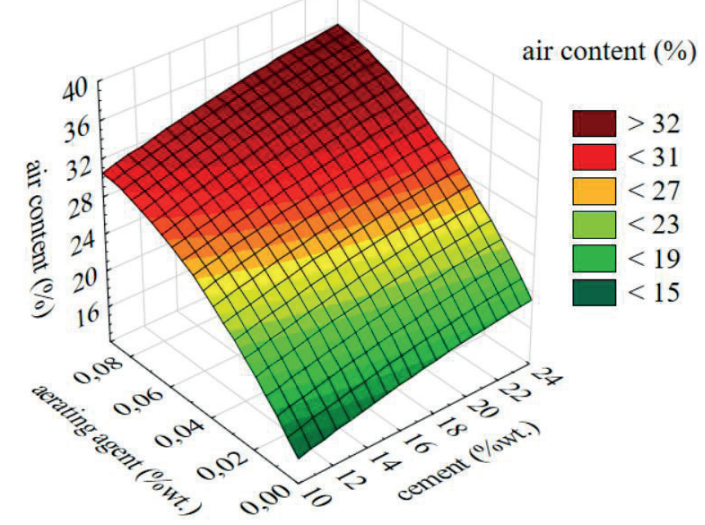

Fig. 4 The impact of aerating agent sodium C14-16 $\alpha$-olefin sulfonate (\%wt.) and cement (\%wt.) on air content L (\%) in fresh mortars

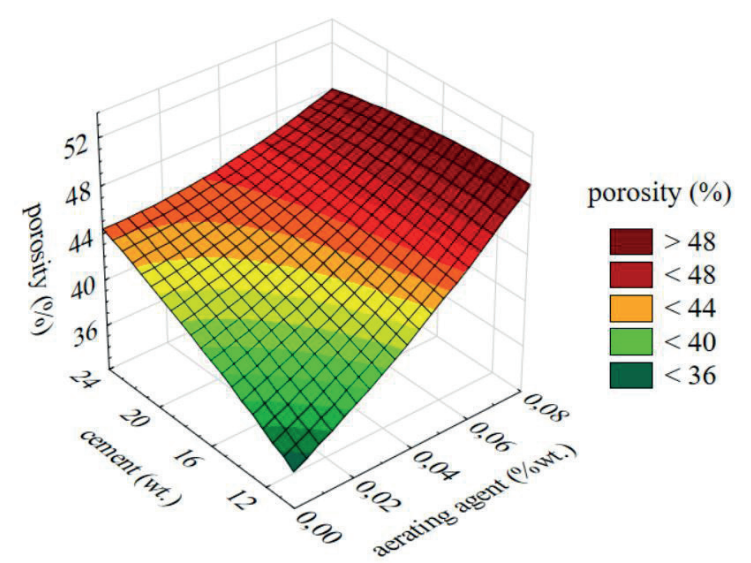

Fig. 5 The impact of aerating agent sodium C14-16 $\alpha$-olefin sulfonate (\%wt.) and cement (\%wt.) on the porosity P (\%) of renovation plasters

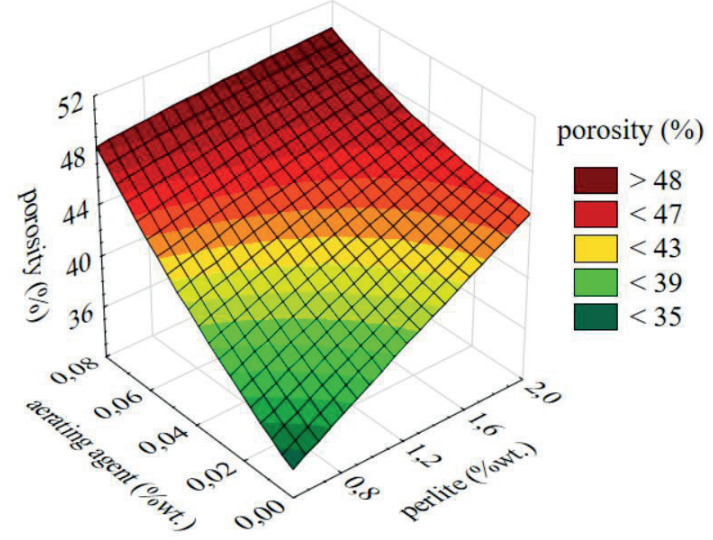

Fig. 6 The impact of perlite (\%wt.) and aerating agent sodium C14-16 $\alpha$-olefin sulfonate (\%wt.) on total porosity $P c$ (\%)

\subsubsection{Aerating agent}

The cement and aerating agent had the greatest impact on the air content. Fig. 4 presents the impact of the amount of cement and aerating agent on the air content $L(\%)$.

When analyzing the contour plot shown in Fig. 4, it can be concluded that in the analyzed cement range the aerating agent affects $L(\%)$ with varying intensity. The highest increase in $L$ is obtained at $0.06 \%$ of aerating agent, and then the impact is slowly decreasing.
In the study of the influence of aerating agent on the total porosity $P c(\%)$ in the examined range of cement quantities (Fig. 5), it was found that the greatest impact of this admixture is at 10 to $20 \%$ of cement content. As the cement content further increases, the influence intensity of aerating agent reduces. The porosity continues to increase, but not as intensively as at lower content of cement.

It can be concluded that aerating agent and cement have a different impact on the air content, and different on the porosity.

\subsubsection{Perlite}

Based on the results obtained, it was concluded that perlite significantly affects porosity, however no impact of this factor on air content was found. Fig. 6 presents the impact of perlite and aerating agent on the porosity of plasters. Analyzing the results, it can be concluded that high porosity can be obtained as a result of changes in the amount of aerating agent and perlite. However, no synergistic impacts of both components on the total porosity of $P c$ were observed.

\subsection{Impact of aerating admixture and perlite on the microstructure of renovating plasters}

Fig. 8 shows the pore size distribution in hardened renovation plasters with porosity of 37 and $42 \%$. The plasters were obtained in recipes 1 and 13 with Taguchi orthogonal design (Table 4). The obtained results were compared with the pore size distribution of the plaster obtained from the recipe containing the optimal amounts of components in the aspect of porosity (Table 5), which are: cement $24 \%$, perlite $2.0 \%$, aerating agent $0.08 \%$, cellulose ether $0.08 \%$ and polymer additive $0.5 \%$. The measurement of pore size distribution was carried using Carlo-Erba 4000 porosimeter.

An important factor, which has the influence on the aeration of the mortars with the use of the aerating agent, is the amount of water in the mixture. When the amount of water is insufficient, the aeration of fresh mortar is low. Fig. 7 presents the impact of $w / c$ ratio of the analysed renovation plasters (recipe 1, 13, and optimal) on the air content (Fig.7a), and flow (Fig.7b).

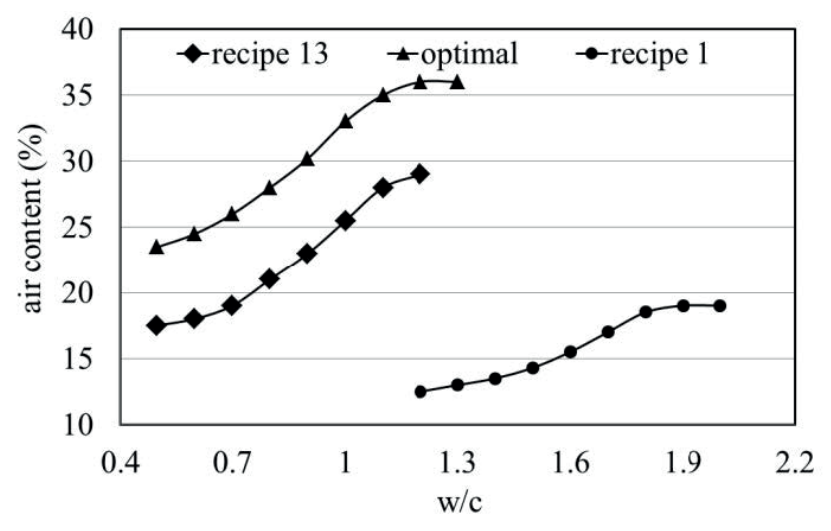

Fig. 7 The impact of $w / c$ on air content in fresh mortars $L$ (\%) (a), and flow $(\mathrm{mm})(\mathrm{b})$ for samples obtained from recipe 1 and 13 (Table 4) compared with the plasters obtained at the optimal amounts of components (Table 5) 


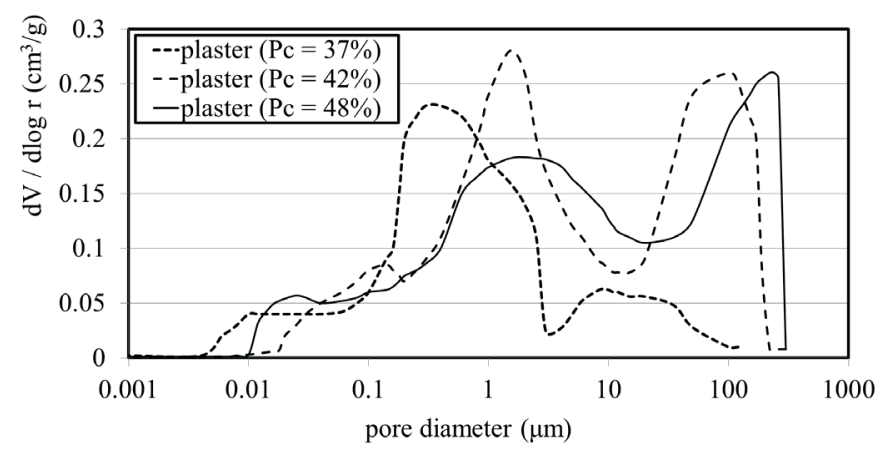

Fig. 8 Differential distribution of pore volume depending on their effective radii for samples of plasters obtained from recipes 1 and 13 (Table 4) compared with plasters obtained at the optimal amount of components (Table 5)
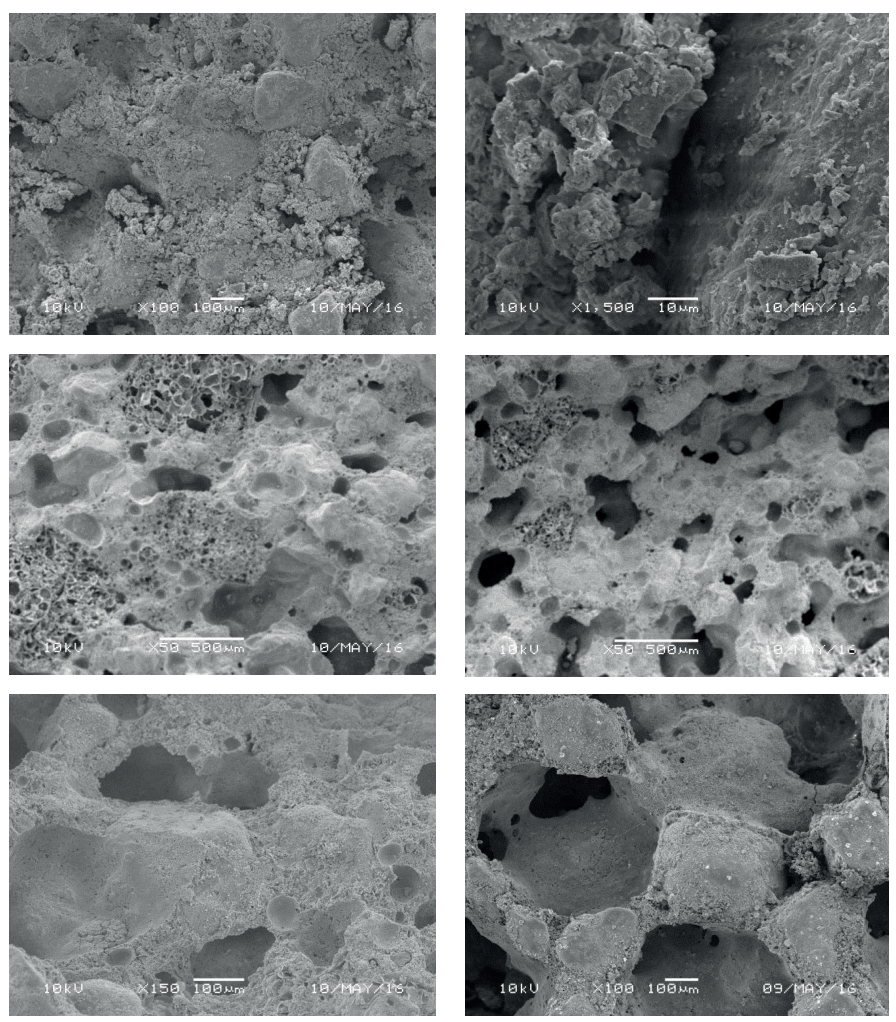

Fig. 9 Photographs of fractures of hardened restoration plaster samples made using SEM, plaster with porosity of $37 \%$ (a and b), plaster with porosity of $42 \%$ (c and d), plaster with porosity of $48 \%(d$ and $f)$

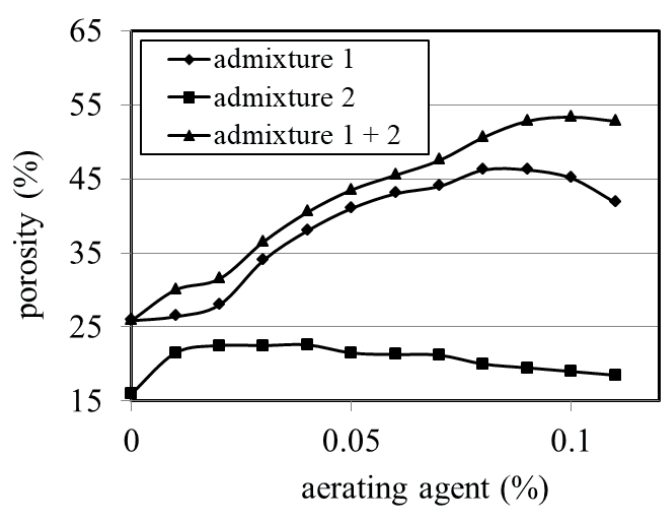

Fig. 10 The impact of the amount of aerating agents: 1 - based on sodium C14-16 $\alpha$-olefin sulfonate 2 - based on sodium lauryl sulfate (SLS) on porosity $P c(\%)$
In Fig. 9, there have been included photographs of fractures of hardened restoration plaster samples made with SEM. Analyzing the results of the research presented in Fig. 8, it can be concluded that the pore size distribution in the plaster varies with the content of the aerating agent and perlite.

For plasters with a porosity of $37 \%$ (obtained from recipe 1 in an orthogonal design, Table 4 ), the amount of perlite was $0.5 \%$, and the aerating agent was $0.01 \%$. The pore size distribution is slightly bimodal. The maximum of pore volumes ranges in diameter from 0.01 to $7 \mu \mathrm{m}$, and from 7 to $100 \mu \mathrm{m}$. On the basis of microscopic observations (Fig. 9a and 9b), it can be concluded that the pores with a diameter below $7 \mu \mathrm{m}$ are partly formed by gaps between the aggregates and the cement matrix. Perlite had an impact on pores with a diameter above $7 \mu \mathrm{m}$. The aerating agent in an amount of $0.01 \%$ was too low to create pores in the plaster.

With the increase of perlite content to $1.5 \%$ and aerating agent to $0.03 \%$ (recipe 13 in the orthogonal design, Table 4) the pore size distribution is clearly bimodal. The maximum of pore volumes ranges in diameter from 0.01 to $30 \mu \mathrm{m}$, and 30 to $300 \mu \mathrm{m}$. Pores with a diameter of up to $30 \mu \mathrm{m}$ in the plaster were influenced by perlite. Next to them, pores with a diameter of $30 \mu \mathrm{m}$ to $300 \mu \mathrm{m}$ appeared, which have a regular spherical shape formed by an aerating agent (Fig. 9c and 9d).

Fig. 9e and $9 \mathrm{f}$ show the renovation plaster fracture obtained with the most favorable amounts of components, resulting from the analysis of optimal values from Taguchi's orthogonal design (Table 5). The most significant impact on porosity was that of perlite in the amount of $2 \%$ and aerating agent in the amount of $0.08 \%$, at the plaster porosity $48 \%$. In the images, two types of pores are visible: one type derived from perlite (the maximum volume in diameter range from $0.01-50 \mu \mathrm{m}$ ), with a characteristic glassy structure. The other type is derived from aerating agent, featuring a spherical shape and sizes from 50 to $300 \mu \mathrm{m}$. The pore size distribution is clearly bimodal.

Fig. 10 presents the impact of the amount of two different aerating agents, the first based on sodium C14-16 $\alpha$-olefin sulfonate - admixture I, the second based on sodium lauryl sulfate (SLS) - admixture II, on porosity Pc (\%). The amount of water in the plaster was optimal, and the porosity was mainly influenced by the type of aerating agent.

It can be stated that with increasing amount of aerating agents in the recipe, the porosity of the hardened plaster increased unevenly. For aerating agent based on sodium C14$16 \alpha$-olefin sulfonate, with amounts of this admixture ranging from 0.0 to $0.02 \%$, the porosity increased more slowly than for the amounts from 0.02 to $0.08 \%$. It reached a maximum pore volume of $48 \%$ with $0.08 \%$. A further increase caused a slight decrease in porosity. For the admixture II, based on sodium lauryl sulfate (SLS), an increase in porosity occurred already with a contents of $0.01 \%$. It was found that with the optimum amount of water in the recipe, the porosity of plasters can be influenced by admixture type and quantities. The 
most important of which include chemical composition, concentration of active substances, molecular mass and structure of polymers it contains [11]. Occurrence of the maximum on the diagram means that there is an upper limit of the aerating agent amount in the plaster, beyond which increase in the amount of the admixture does not affect the porosity. Increasing the porosity by more than $10 \%$ was achieved by the simultaneous use of two different admixtures in the recipe.

The observed phenomenon can be explained by the impact of the aerating agent (admixture 1) on the change in surface tension of the batched water. At low doses the surface tension of water is not changed. This is due to the fact that small amounts of admixture 1 are first adsorbed on the surface of solids, and it is the admixture in the liquid phase that is responsible for the formation of foam. On the other hand, with excessive admixture amounts, the formation of micelles occurs, in which aerating agents are trapped and do not take part in the formation and stabilization of the foam. Surface tension is also not reduced by the micelles formed [10].

\section{Conclusions}

On the basis of the research, it can be concluded that the use of the Taguchi method to shape the porosity of renovation plasters allowed to identify the components that have the greatest impact on porosity and to determine the optimal amounts of these components in the recipe.

The optimization of recipes using the Taguchi method was performed on a small number of experiments, which allowed to significantly shorten the time and save on costs.

Thanks to the obtained recipes, further research on the influence of aerating agents on porosity was carried out, with the determined optimal amounts of the other components.

As a result of these further studies, it was established that there is an upper limit of the amount of aerating agent in the plaster, beyond which increasing the amount of admixtures does not affect the porosity.

Increasing the porosity by more than $10 \%$ was achieved by the simultaneous use of two different admixtures in the recipe.

\section{References}

[1] Lubelli, B., van Hees, R. P. J., Groot, C. W. P. "Investigation on the behaviour of a restoration plaster applied on heavy salt loaded masonry". Construction and Building Materials, 20(9), pp. 691-699. 2006. https://doi.org/10.1016/j.conbuildmat.2005.02.010

[2] Michoinová, D. "Questions about renovation plasters". Zprávy památkové péče, (65), pp. 313-316. 2005.

[3] Pavlíková, M., Pavlík, Z., Keppert, M., Černy, R. "Salt transport and storage parameters of renovation plasters and their possible effects on restored buildings' walls". Construction and Building Materials, 25(3), pp. 1205 1212. 2011.

https://doi.org/10.1016/j.conbuildmat.2010.09.034

[4] Vejmelková, E., Keppert, M., Keršner, Z., Rovnaníková, P., Černy, R. "Mechanical, fracture-mechanical, hydric, thermal, and durability properties of lime-metakaolin plasters for renovation of historical buildings". Construc- tion and Building Materials, 31, pp. 22-28. 2012.

https://doi.org/10.1016/j.conbuildmat.2011.12.084

[5] Brachaczek, W., Magott, C. "Analysis of errors in restoration of salty and damp walls". In: Proceeding of The Third International Conference On Advances in Civil, Structural and Mechanical Engineering, pp. 33-37. 28-29. December, Bangkok, Thailand, 2015.

https://doi.org/10.15224/978-1-63248-083-5-22

[6] WTA Merkblatt 2-9-04/D:2005-10, "Sanierputzsysteme. Renovation mortarsystems". Technische Regel. 2005.

[7] Glinicki, M. "Właściwe i patologiczne napowietrzanie betonu". (The appropriate and pathological aeration of concrete). Budownictwo-Technologie-Architektura, 2. pp. 37-40. 2004. (in Polish).

[8] Giergiczny, Z., Glinicki, M. A., Sokołowski, M., Zielinski, M. "Air void system and frost-salt scaling of concrete containing slag-blended cement". Construction and Building Materials, 23(6), pp. 2451-2456. 2009.

https://doi.org/10.1016/j.conbuildmat.2008.10.001

[9] Chatterji, S. "Freezing of air-entrained cement-based materials and specific actions of air-entraining agents". Cement and Concrete Composites, 25(7) pp. 759-765. 2003.

https://doi.org/10.1016/S0958-9465(02)00099-9

[10] Du, L., Folliard, K. J. "Mechanisms of air entrainment in concrete". Cement and Concrete Research, 35(8), pp. 1463-1471. 2005.

https://doi.org/10.1016/j.cemconres.2004.07.026

[11] Powers, T. C., Willis, T. F. "The air requirement of frost resistant concrete". In: Proceedings of the Twenty-Ninth Annual Meeting of the Highway Research Board Held at Washington, D.C. December 13-16, 1949.

[12] Powers, T. C. "The Properties of Fresh Concrete". John Wiley \& Sons, New York, 1968.

[13] Backstrom, J. E., Burrows, R. W., Mielenz, R. C., Wolkodoff, V. E. "Origin, Evolution, and Effects of the Air Void System in Concrete. Part 2. Influence of type and amount of air-entraining agent". Journal Proceedings, 55. pp. 261-272. 1958.

[14] Sugiura, A., Sakakibara, H., Kobayashi, S. "Influences of types of cement and redispersible polymer powder on properties of polymer-modified mortars". Journal of the Society of Materials Science, 48(8). pp. 853-857. 1999. https://doi.org/10.2472/jsms.48.853

[15] Singh, M., Garg, M. "Perlite-based building materials - a review of current applications". Construction and Building Materials, 5(2), pp. 75-81. 1991. https://doi.org/10.1016/0950-0618(91)90004-5

[16] Celik, A. G., Kilic, A. M., Cakal, G. O. "Expanded perlite aggregate characterization for use as a lightweight construction raw material". Physicochemical Problems of Mineral Processing, 49(2), pp. 689-700. 2013.

[17] Hover, K. C. "Vibration tune-up". Concrete International, American Concrete Institute, Farmington Hills, Michigan, pp. 31-35. 2001.

[18] Ruta, R. "Zastosowanie metody Taguchiego planowania eksperymentów w badaniach tribologicznych". (The application of a planning method by Taguchi in tribiological researches). 2, pp. 125-141. 2011. (in Polish)

[19] Bochetyn, B., Kubisz, B. "Planowanie eksperymentu". (The planning of an experiment). LAB Laboratoria, Aparatura, Badania, 20(2), pp. 34-39. 2015. (in Polish)

[20] PN-EN 1015-2:2000/A1:2007E: Methods of test for mortar for masonry Part 2: Bulk sampling of mortars and preparation of test mortars.

[21] PN-EN 1015-11:2001/A1:2007:Methods of test for mortar for masonry - Part 11: Determination of flexural and compressive strength of hardened mortar.

[22] PN-EN 1015-3:2000/A2:2007E, Methods of test for mortar for masonry Part 3: Determination of consistency of fresh mortar (by flow table), 2000.

[23] Gray, C. T. "Introduction to quality engineering: designing quality into products and processes, G. Taguchi, Asian productivity organization". Quality and Reliability Engineering International, 4(2), p. 198. 1988. https://doi.org/10.1002/qre.4680040216 